\title{
MANAJEMEN BANDWIDTH MELALUI IP FILTER MIKROKTIK HAP LITE DI FT UNISKA
}

\author{
${ }^{1}$ Novi Ari Saputro \\ ${ }^{1}$ Teknik Elektro, Fakultas Teknk Universitas Islam Kadiri \\ 1nopiari75@gmail.com
}

\begin{tabular}{l} 
Article Info \\
Article history: \\
Received September $10^{\text {th }}, 2021$ \\
Revised October $13^{\text {th }}, 2021$ \\
Accepted October $19^{\text {th }}, 2021$ \\
\hline Keyword: \\
Mikrotik Hap Lite \\
QoS \\
Throughput \\
Packet Loss \\
Delay \\
Jitter
\end{tabular}

\section{Corresponding Author: Novi Ari Saputro \\ Teknik Elektro, Fakultas Teknk Universitas Islam Kadiri nopiari75@gmail.com}

Abstrak-Manajemen bandwidth untuk client yang terhubung pada jaringan internet sangat dibutuhkan dalam proses upload dan download. Dalam penelitian ini digunakan perangkat tambahan berupa router mikrotik dan lokasi penelitian di Fakultas Teknik UNISKA, Kediri. Penelitian membahas tentang Quality of Service (QoS) dengan 4 indikator yaitu throughput, packet loss, delay, dan jitter. Hasil penelitian menunjukkan pada aplikasi speedtest bandwidth tidak melebihi batas limit yang ditentukan. Serta pada aplikasi wireshark ditunjukkan perhitungan QoS Throughput setiap user didapatkan tidak lebih dari $100 \mathrm{Kbps}$, maka parameter standar menurut TIPHON dikategorikan "BAD" dengan index "0". Pada QoS packet loss setiap user didapatkan nilai 0 , maka parameter standar menurut TIPHON dikategorikan "PERFECT" dengan index "4". Pada QoS delay setiap user didapatkan nilai kurang dari $100 \mathrm{~s}$, maka parameter standar menurut TIPHON dikategorikan "PERFECT" dengan index "4". Dan pada QoS jitter setiap user didapatkan nilai dibawah angka 1, maka parameter standar menurut TIPHON dikategorikan "GOOD” dengan index "3".

\section{Pendahuluan}

Manajemen bandwidth adalah suatu cara yang dapat digunakan untuk manajemen dan mengoptimalkan berbagai jenis jaringan dengan menerapan layanan Quality of Service (QoS) untuk menetapkan tipe-tipe lalulintas jarngan. Sedangkan QoS adalah kemampuan untuk menggambarkan suatu tingkatan pencapaian didalam suatu sistem komunikasi data [1]. Jaringan internet yang memiliki kapasitas user yang besar sangat terganggu bila tanpa adanya manajemen bandwith, akibatnya penggunaan bandwith internet tidak terbagi merata, serta traffic internet tidak tertata. Hal ini mengakibatkan akses internet mejadi kurang optimal.

Mikrotik adalah sistem operasi Linux base yang diperuntukkan sebagai network router, serta didesain untuk memberikan kemudahan bagi penggunanya [2]. Akses mikrotik dapat menggunakan aplikasi windows application (WInBox). Selain dipakai instalasi (setting bandwith) dapat pula dilakukan pada standart komputer (PC). Mikrotik tebagi menjadi 2 yaitu mikrotik Router OS dan mikrotik Router Board.

Mikrotik hap lite merupakan mikrotik router board yang termasuk dalam tipe 900 yang memungkinkan dapa digunakan dalam berbagai kondisi. Dan juga didukung dengan support berbagai fitur aplikasi router OS, serta dapat diaplikasi di rumah maupun kantor.

Quality of Service (QoS) adalah metode pengukuran yang digunakan untuk menentukan kemampuan sebuah jaringan seperti aplikasi jaringan, router dengan tujuan memberikan network service yang lebih baik dan terencana sehingga dapat memenuhi kebutuhan suatu layanan [3]. Tujuan dari QoS 
menawarkan kemampuan untuk mengartikan indikator layanan yang disediakan, baik itu berupa kualitatif maupun kuantitatif, serta menyediakan kualitas layanan yang berbedabeda berdasarkan kebutuhan layanan di dalam jaringan tersebut.

Indikator QoS terbagi menjadi 4 yaitu Throughput : kemampuan sebenarnya suatu jaringan dalam melakukan pengiriman data, Jitter : variasi atau perubahan latency dari delay atau variasi waktu kedatangan paket, Packet loss : parameter yang menggambarkan suatu kondisi yang menunjukkan jumlah total paket yang hilang, Delay : total waktu tunda suatu paket yang diakibatkan oleh proses transmisi dari satu titik ke titik lain yang menjadi tujuannya $[4]$.

\section{Metode Penelitian}

Dalam penelitian ini penulis menggunakan penelitian kuanitatif yaitu penelitian yang berupa data angka dari penelitian yang dilakukan oleh peneliti. Adapun metode yang digunakan dalam penulisan ini adalah metode deskriptif. Metode deskriptif, dapat diartikan sebagai prosedur atau cara memecahkan masalah penelitian dengan memaparkan keadaan objek yang diselidiki.

\section{A. Bahan Penelitian}

Analisa kebutuhan penelitian dilakukan untuk mengidentifikasi kebutuhan bandwidth yang dipakai di Fakultas Teknik Universitas Islam Kadiri, kebutuhan komponen perangkat keras (hardware) antara lain Mikrotik Routerboard RB941-2nd, Kabel UTP, RJ 45, Tang crimping, Tester. dan kebutuhan perangkat lunak (software) antara lain OS Mikrotik, Virtual Box, Winbox, dan Cisco Packet Tracer.

\section{B. Rancangan Penelitian}

Rancangan penelitian dibagi dalam dua tahapan, yaitu rancangan topologi jaringan serta rancangan hardware dan software.

\section{Rancangan Topologi Jaringan}

Topologi jaringan terbagi menjadi 7 yaitu topologi ring, bus, star, mesh, tree, peer to peer, serta linier [5]. Rancangan topologi yang dipakai penelitian yaitu topologi star yang memiliki kelebihan dibanding dengan topologi yang lain antara lain tetap berjalan dengan baik walaupun ada salah satu client yang bermasalah, tingkat keamanan data cukup baik, pengguna lebih mudah mendeteksi masalah pada jaringan, serta lebih fleksibel.

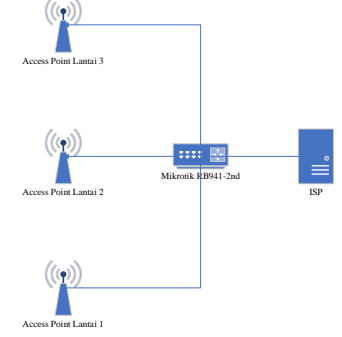

Gambar 1. Rancangan Topologi Star [5]

Terlihat gambar 1 dibentuk sesuai kebutuhan di FT UNISKA. Dengan pembagian sesuai jumlah lantai di Gedung Fakultas dengan membagi setiap lantai diberi 1 access point.

2. Rancangan Hardware dan Software

Rancangan hardware dibagi dalam beberapa konfigurasi antara lain : konfigurasi router utama, konfigurasi hotspot, konfigurasi user, integrasi hotspot mikrotik dengan user profile, dan setting batasan user profil.

Konfigurasi router utama harus dilakukan pemilihan port pada routerboard yang akan disambungkan serta dilakukan setting DHCP server pada port yang akan ditempati sebagai port masuk dari layanan provider. Setelah itu, konfigurasi hotspot yang bertujuan untuk memudahkan pemasangan router client. Kemudian konfigurasi user untuk memudahkan mengakses hotspot yang disiapkan sebelumnya.

Konfigurasi selanjutnya yaitu integrasi hotspot mikrotik dengan user profil yang ditujukan untuk membatasi penggunaan koneksi internet dengan otentifikasi menggunakan halaman login pada web browser, serta dilakukan seting manajemen bandwith pada mikrotik. Selanjutnya setting batasan user profil untuk membatasi akses penggunaan melalui bandwith tanpa batasan waktu.

Rancangan software membutuhkan winbox yang support dengan Mikrotik OS yang terdapat didalam Routerboard dan add-on untuk user manager. Sistem yang digunakan disini adalah hotspot mikrotik dengan sistem login, adapun flowchart yang digunakan sebagai berikut. 


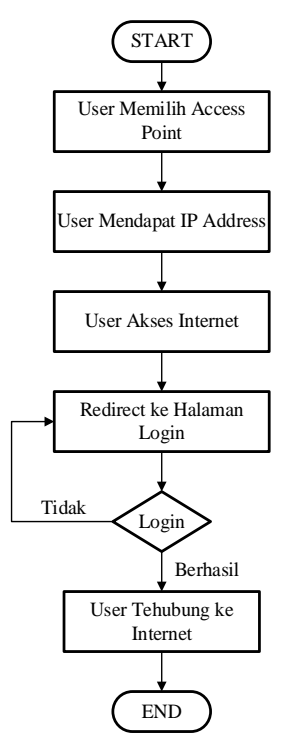

Gambar 2. Flowchart Sistem Jaringan

\section{Manajemen Bandwith}

Manajemen bandwith dilakukan pada dua konfigurasi, yaitu IP addres serta limitasi user.

1. IP Address

Setting IP Address harus dibagi sesuai jumlah maksimal yang memakai dalam akses jaringan internet agar tidak terjadi konflik. IP digunakan untuk pengalamatan sebuah perangkat sehingga perlu dirancang sedemikian rupa agar lebih memudahkan dalam implementasi. Berikut ini rancangan IP yang digunakan dalam bentuk tabel.

Tabel 1. Rancangan IP Address

\begin{tabular}{|c|c|c|c|}
\hline Interface & IP Address & Netmask & Gateway \\
\hline Ethernet 1 & DHCP & DHCP & DHCP \\
\hline Ethernet 2 & $192.168 .30 .1 / 24$ & 255.255 .255 .0 & 192.168 .30 .1 \\
\hline Ethernet 3 & $192.168 .30 .1 / 24$ & 255.255 .255 .0 & 192.168 .30 .1 \\
\hline Ethernet 4 & $192.168 .30 .1 / 24$ & 255.255 .255 .0 & 192.168 .30 .1 \\
\hline WLAN Interface & $192.168 .30 .1 / 24$ & 255.255 .255 .0 & 192.168 .30 .1 \\
\hline
\end{tabular}

Terlihat pada tabel 1 untuk Ethernet 3 dan tidak diberikan alamat IP karena tiga port ini masih belum digunakan, nantinya akan diperlukan jika ada penambahan jaringan yang lebih kompleks lagi. Pada ethernet1 dituliskan DHCP karena nantinya untuk Ethernetl akan diaktifkan fitur DHCP Client agar nantinya lebih mudah jika router dipindah ke router lain atau langsung dari modem. Namun ada beberapa kelemahan diantaranya adalah harus setting ulang IP pada User Manager dengan IP baru, jika dipindah.

\section{Limitasi User}

Limitasi user penulis memberikan 1 user di setiap jurusan yang nantinya bisa digunakan untuk login bersamaan. Hal ini memudahkan admin jaringan dalam memonitor siswa mana yang sedang menggunakan hotspot. Berikut ini tabel perancangan user.

Tabel 2. User dan Password pada setting 1

\begin{tabular}{|c|c|c|c|}
\hline Nama User & Password & Limitasi & Masa Aktif \\
\hline dosen & dosen & $4 \mathrm{M} / 4 \mathrm{M}$ & Unlimited \\
\hline staff & staff & $2 \mathrm{M} / 2 \mathrm{M}$ & Unlimited \\
\hline mahasiswa & mahasiswa & $4 \mathrm{M} / 4 \mathrm{M}$ & Unlimited \\
\hline
\end{tabular}

Terlihat pada tabel 2 pembagian bandwith terbagi menjadi 3 yaitu dosen, staff, dan mahasiswa. Dengan limitasi dengan perbadingan upload $=$ download. Terlihat pada bagian mahasiswa dan dosen lebih besar dari staff. Hal ini dikarenakan akses mahasiswa dan dosen lebih besar dari pada staff.

Tabel 3. User dan Password pada setting 2

\begin{tabular}{|c|c|c|c|}
\hline Nama User & Password & Limitasi & Masa Aktif \\
\hline dosen & dosen & $4 \mathrm{M} / 10 \mathrm{M}$ & Unlimited \\
\hline staff & staff & $2 \mathrm{M} / 10 \mathrm{M}$ & Unlimited \\
\hline mahasiswa & mahasiswa & $4 \mathrm{M} / 10 \mathrm{M}$ & Unlimited \\
\hline
\end{tabular}

Terlihat pada tabel 3 pembagian bandwith terbagi menjadi 3 yaitu dosen, staff, dan mahasiswa. Dengan limitasi dengan perbadingan upload $=<$ download, dengan tujuan ketika pengguna terus bertambah maka bandwith akan terbagi sendiri.

\section{A. Pengujian}

\section{Hasil dan Pembahasan}

Penelitian ini menggunakan Internet Service Provider (ISP) dari Telkom yaitu indihome dengan paket up to 10 Mbps. Dalam setting mikrotik peneliti menggunakan 2 model setting mikrotik antara lain pembagian bandwidth di user profile dan pembagian bandwidth menggunakan mark packet serta queue tree, dengan manajemen bandwidth seperti berikut.

$>$ Pembagian bandwidth di user profile, untuk setting ini peneliti memberikan bandwidth untuk tiap user profile dengan perbandingan $1: 1$, tanpa memberi setting variasi yang lain. Dengan rincian pembagian sebagai berikut.

- $\quad$ Mahasiswa $=4 \mathrm{M} / 4 \mathrm{M}$

- $\quad$ Dosen $=4 \mathrm{M} / 4 \mathrm{M}$

- $\quad$ Staff $=2 \mathrm{M} / 2 \mathrm{M}$

Pembagian bandwidth menggunakan mark packet dan queue tree, untuk setting ini peneliti memberikan bandwidth pada pilihan mark packet dan queue tree. Manajemen bandwidthnya untuk receivernya lebih 
besar dari transmitternya. Dengan rincian pembagian sebagai berikut.

- $\quad$ Mahasiswa $=4 \mathrm{M} / 10 \mathrm{M}$

- Dosen $=4 \mathrm{M} / 10 \mathrm{M}$

- $\quad$ Staff $=2 \mathrm{M} / 10 \mathrm{M}$

Pada pengujian penelitian ini peneliti memakai 1 laptop dan 1 smartphone dengan menggunakan parameter pengukuran antara lain menggunakan aplikasi speedtest dan aplikasi wireshark. Berikut hasil pengujian penelitian sebagai berikut.

1. Pengujian pada setting pembagian bandwidth pada user profil

a. Mahasiswa
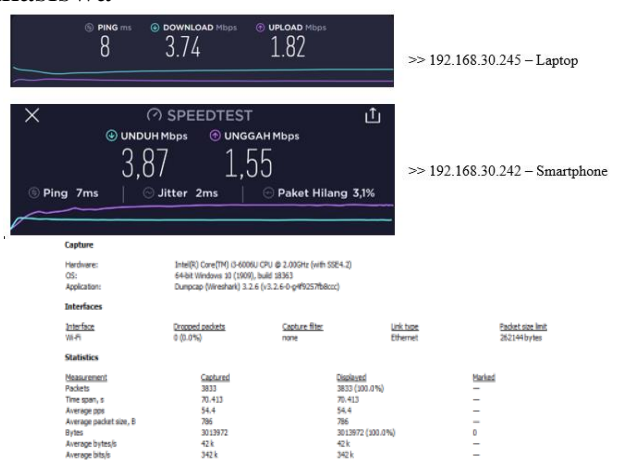

Gambar 3. Pengukuran Mahasiswa Setting 1 Speedtest dan Wireshark 2.6

Perhitungan wireshark 2.6 mengikuti metode standar TIPHON

Throughput $=42804,1981 \mathrm{byte} / \mathrm{s}=42,804 \mathrm{Kbps}$

Packet Loss $\quad=0 \%$

Delay $\quad=70,412843 \mathrm{~s}$

rata-rata delay $=0,018370165 \mathrm{~s}=18,37 \mathrm{~ms}$

Jitter $\quad=0,311058 \mathrm{~s}$

rata-rata jitter $\quad=0,00008117 \mathrm{~s}=0,08117 \mathrm{~ms}$

b. Dosen

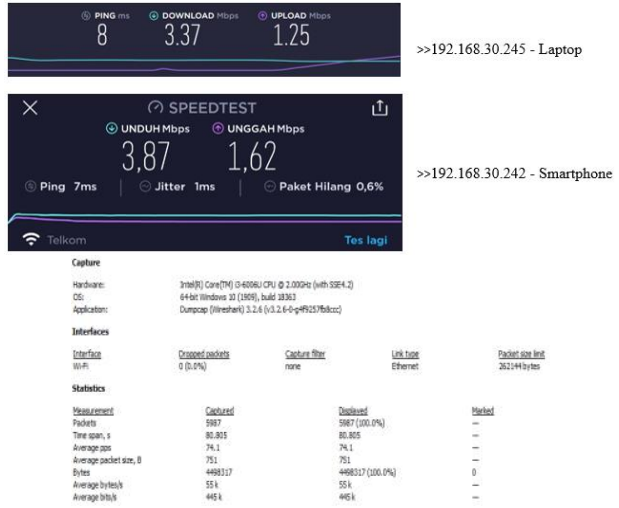

Gambar 4. Pengukuran Dosen Setting 1 Speedtest dan Wireshark 2.6
Perhitungan wireshark 2.6 mengikuti metode standar TIPHON

Throughput $=55668,77952$ byte $/ \mathrm{s}=55,668 \mathrm{Kbps}$

Packet Loss $=0 \%$

Delay $\quad=80,049117 \mathrm{~s}$

rata-rata delay $=00,013370489 \mathrm{~s}=13,37 \mathrm{~ms}$

Jitter $\quad=0,035339 \mathrm{~s}$

rata-rata jitter $\quad=0,000005904 \mathrm{~s}=0,005904 \mathrm{~ms}$

c. Staff

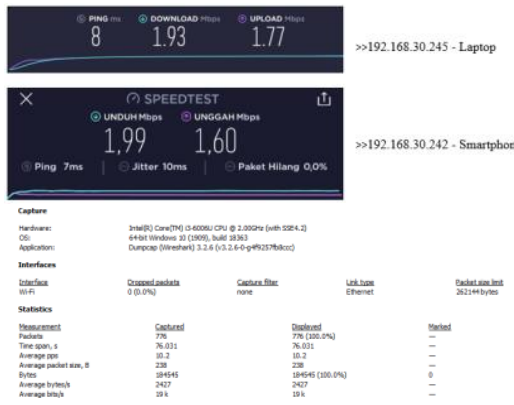

Gambar 5. Pengukuran Staff Setting 1 Speedtest dan Wireshark 2.6

Perhitungan wireshark 2.6 mengikuti metode standar TIPHON

Throughput $=2427,23363 \mathrm{byte} / \mathrm{s}=2,427 \mathrm{Kbps}$

Packet Loss $=0 \%$

Delay $\quad=76,031087 \mathrm{~s}$

rata-rata delay $=0,097978205 \mathrm{~s}=97,98 \mathrm{~ms}$

Jitter $\quad=0,718202 \mathrm{~s}$

rata-rata jitter $\quad=0,000926712 \mathrm{~s}=0,9267 \mathrm{~ms}$

2. Pengujian pada setting pembagian bandwidth menggunakan mark packet dan queue tree menggunakan mark packet dan queue tree

a. Mahasiswa

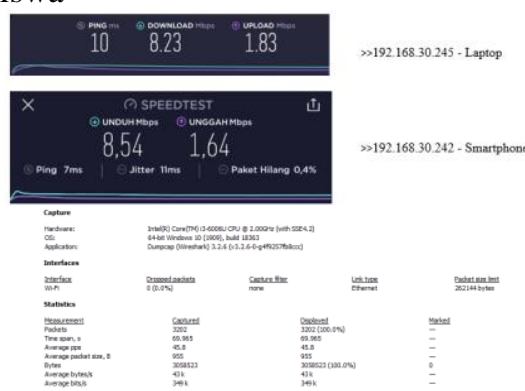

Gambar 6. Pengukuran Mahasiswa Setting 2 Speedtest dan Wireshark 2.6

Perhitungan wireshark 2.6 mengikuti metode standar TIPHON

Throughput $=43884,3963$ byte $/ \mathrm{s}=43,884 \mathrm{Kbps}$

Packet Loss $=0 \%$

Delay $\quad=64,730036 \mathrm{~s}$

rata-rata delay $\quad=0,020215502 \mathrm{~s}=20,22 \mathrm{~ms}$

Jitter $=2,124228 \mathrm{~s}$ 
rata-rata jitter $\quad=0,000663614 \mathrm{~s}=0,6636 \mathrm{~ms}$

b. Dosen

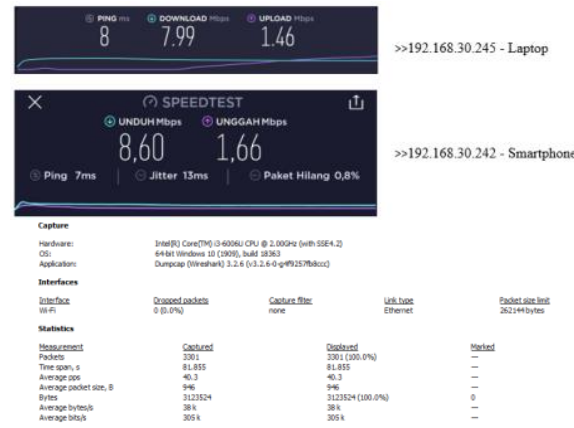

Gambar 7. Pengukuran Dosen Setting 2 Speedtest dan Wireshark 2.6

Perhitungan wireshark 2.6 mengikuti metode standar TIPHON
Throughput $=38159,2328$ byte $/ \mathrm{s}=38,159 \mathrm{Kbps}$
Packet Loss $=0 \%$
Delay $\quad=70,605057 \mathrm{~s}$

rata-rata delay $\quad=0,020215502 \mathrm{~s}=20,22 \mathrm{~ms}$

Jitter $=0,288566 \mathrm{~s}$

rata-rata jitter $\quad=0,00008744424 \mathrm{~s}=0,0874 \mathrm{~ms}$

c. Staff

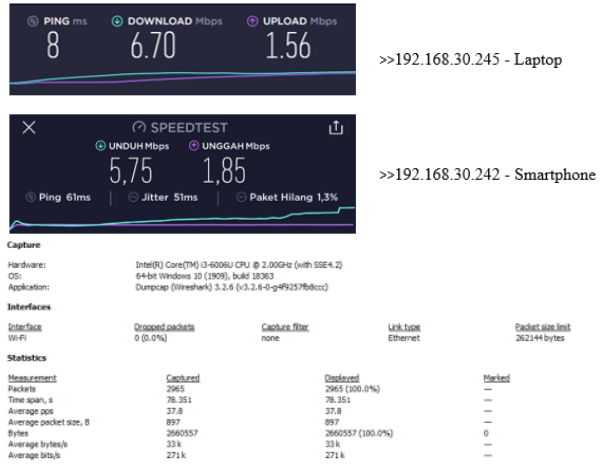

Gambar 8. Pengukuran Staff Setting 2 Speedtest dan

Wireshark 2.6

Perhitungan wireshark 2.6 mengikuti metode standar TIPHON

Throughput $=33956,8991 \mathrm{byte} / \mathrm{s}=33,957 \mathrm{Kbps}$

Packet Loss $=0 \%$

Delay $\quad=76,66678 \mathrm{~s}$

rata-rata delay $=0,025857261 \mathrm{~s}=25,85 \mathrm{~ms}$

Jitter $\quad=0,121289 \mathrm{~s}$

rata-rata jitter $=0,0000442282726 \mathrm{~s}=0,0443 \mathrm{~ms}$

\section{B. Hasil Pengujian}

Hasil dari pengujian penelitian dapat dilihat pada tabel dibawah ini.
Tabel 4. Hasil Pengujian Dengan Speedtest

\begin{tabular}{|c|c|c|c|c|c|c|}
\hline \multirow{2}{*}{ NO } & \multirow{2}{*}{ Nama Perangkat } & \multirow{2}{*}{ IP Address } & \multirow{2}{*}{ User Login } & \multirow{2}{*}{ Model } & \multicolumn{2}{|c|}{$\begin{array}{l}\text { Pengukuran bandwidth } \\
\text { (Mbps) }\end{array}$} \\
\hline & & & & & Download & Upload \\
\hline 1 & Laptop Asus X441U & \begin{tabular}{|l|}
192.168 .30 .245 \\
\end{tabular} & mahasiswa & \multirow{6}{*}{ Setting 1} & 3,74 & 1,82 \\
\hline 2 & HP Asus Max Pro M1 & $\begin{array}{l}192.168 .30 .242 \\
\end{array}$ & mahasiswa & & 3,87 & 1,55 \\
\hline 3 & Laptop Asus X441U & \begin{tabular}{|l|}
192.168 .30 .245 \\
\end{tabular} & dosen & & 3,37 & 1,25 \\
\hline 4 & HP Asus Max Pro M1 & \begin{tabular}{|l|}
192.168 .30 .242 \\
\end{tabular} & dosen & & 3,87 & 1,62 \\
\hline 5 & Laptop Asus X441U & \begin{tabular}{|l|}
192.168 .30 .245 \\
\end{tabular} & staff & & 1,93 & 1,77 \\
\hline 6 & HP Asus Max Pro M1 & \begin{tabular}{|l|}
192.168 .30 .242 \\
\end{tabular} & staff & & 1,99 & 1,60 \\
\hline 7 & Laptop Asus X441U & \begin{tabular}{|l|l|}
192.168 .30 .245 \\
\end{tabular} & mahasiswa & \multirow{6}{*}{ Setting 2} & 8,23 & 1,83 \\
\hline 8 & HP Asus Max Pro M1 & \begin{tabular}{|l|}
192.168 .30 .242 \\
\end{tabular} & mahasiswa & & 8,54 & 1,64 \\
\hline 9 & Laptop Asus X441U & \begin{tabular}{|l|}
192.168 .30 .245 \\
\end{tabular} & dosen & & 7.99 & 1,46 \\
\hline 10 & HP Asus Max Pro M1 & \begin{tabular}{|l|l|}
192.168 .30 .242 \\
\end{tabular} & dosen & & 8,60 & 1,66 \\
\hline 11 & Laptop Asus X441U & \begin{tabular}{|l|}
192.168 .30 .245 \\
\end{tabular} & staff & & 6,70 & 1,56 \\
\hline 12 & HP Asus Max Pro M1 & \begin{tabular}{|l|}
192.168 .30 .242 \\
\end{tabular} & staff & & 5,75 & 1,75 \\
\hline
\end{tabular}

Pada tabel 4 dapat dijelaskan bahwa pengolahan bandwidth dengan menggunakan batas limit yang dilakukan pada 2 model manajemen yang ada di atas akan mengalami penggunaan bandwidth yang merata tidak melebihi batas yang ditentukan sebelumnya kepada setiap user dari mahasiswa, dosen dan staff. Dengan demikian tidak menyebab kan terjadinya pemakaian bandwidth yang berlebihan atau bandwidth overload.

Tabel 5. Hasil QoS Throughput Dengan Wireshark

\begin{tabular}{|c|c|c|c|c|c|c|}
\hline No & User Login & IP Addres & \multirow{2}{*}{ Model } & $\begin{array}{c}\text { Throughput } \\
\text { (Kbps) }\end{array}$ & Index & Kategori \\
\hline 1 & mahasiswa & 192.168 .30 .245 & & \multirow{3}{*}{ Setting 1 12,804} & 0 & $\mathrm{Bad}$ \\
\hline 2 & dosen & 192.168 .30 .245 & 55,668 & 0 & $\mathrm{Bad}$ \\
\hline 3 & staff & 192.168 .30 .245 & & 2,427 & 0 & $\mathrm{Bad}$ \\
\hline 4 & mahasiswa & 192.168 .30 .245 & & 43,884 & 0 & $\mathrm{Bad}$ \\
\hline 5 & dosen & 192.168 .30 .245 & \multirow{2}{*}{ Setting 2 2} & 38,159 & 0 & $\mathrm{Bad}$ \\
\hline 6 & staff & 192.168 .30 .245 & & 33,957 & 0 & $\mathrm{Bad}$ \\
\hline
\end{tabular}

Pada tabel 5 menunjukkan perhitungan Quality of Service (QoS) Throughput pada setiap user yang didapatkan tidak lebih dari 100 Kbps. Perhitungan QoS Throughput didapatkan pada kategori "BAD" dengan nilai index "0", karena perhitungan yang didapatkan pada range $0-338 \mathrm{Kbps}$. Hal ini dipengaruhi oleh internet kurang lancar dan perangkat yang mendukung masih dibawah rata-rata.

Tabel 6. Hasil QoS Packet Loss Dengan Wireshark

\begin{tabular}{|c|c|c|c|c|c|c|}
\hline No & User Login & IP Addres & Model & Packet Loss & Index & Kategor \\
\hline 1 & mahasiswa & 192.168 .30 .245 & \multirow{3}{*}{ Setting 1} & $0 \%$ & 4 & Perfect \\
\hline 2 & dosen & 192.168 .30 .245 & & $0 \%$ & 4 & Perfect \\
\hline 3 & staff & 192.168 .30 .245 & & $0 \%$ & 4 & Perfect \\
\hline 4 & mahasiswa & 192.168 .30 .245 & \multirow{3}{*}{ Setting 2} & $0 \%$ & 4 & Perfect \\
\hline 5 & dosen & 192.168 .30 .245 & & $0 \%$ & 4 & Perfect \\
\hline 6 & staff & 192.168 .30 .245 & & $0 \%$ & 4 & Perfect \\
\hline
\end{tabular}

Pada table 6 menunjukkan perhitungan Quality of Service (QoS) packet loss pada setiap user mendapatkan nilai $0 \%$. Maka didapatkan pada kategori "PERFECT" dengan nilai index "4". Artinya pada penelitian manajemen bandwith tidak ditemukan data paket yang hilang.

Tabel 7. Hasil Qos Delay Dengan Wireshark

\begin{tabular}{|c|c|c|c|c|c|c|}
\hline No & User Login & IP Addres & Model & Delay (s) & Index & Kategori \\
\hline 1 & mahasiswa & 192.168 .30 .245 & \multirow{3}{*}{ Setting 1} & 70,413 & 4 & Perfect \\
\hline 2 & dosen & 192.168 .30 .245 & & 80,049 & 4 & Perfect \\
\hline 3 & staff & 192.168 .30 .245 & & 76,031 & 4 & Perfect \\
\hline 4 & mahasiswa & 192.168 .30 .245 & \multirow{3}{*}{ Setting 2} & 64,73 & 4 & Perfect \\
\hline 5 & dosen & 192.168 .30 .245 & & 70,605 & 4 & Perfect \\
\hline 6 & staff & 192.168 .30 .245 & & 76,667 & 4 & Perfect \\
\hline
\end{tabular}


Pada table 7 menunjukkan perhitungan Quality of Service (QoS) delay pada setiap user mendapatkan nilai masih dibawah 100 s. Maka mendapatkan kategori "PERFECT" dengan nilai index " 4 " dengan range < 150 s. Artinya waktu tunda pengiriman paket data sangat kecil sehingga akses internet sangat lancar dan stabil.

Tabel 8. Hasil QoS Jitter Dengan Wireshark

\begin{tabular}{|c|c|c|c|c|c|c|}
\hline No & User Login & IP Addres & Model & Jitter $(\mathbf{m s})$ & Index & Kategori \\
\hline 1 & mahasiswa & 192.168 .30 .245 & & 0,08117 & 3 & Good \\
\hline 2 & dosen & 192.168 .30 .245 & \multirow{2}{*}{ Setting 1 1} & 0,005904 & 3 & Good \\
\cline { 5 - 7 } \cline { 5 - 7 } & staff & 192.168 .30 .245 & & 0,9267 & 3 & Good \\
\hline 4 & mahasiswa & 192.168 .30 .245 & & 0,6636 & 3 & Good \\
\hline 5 & dosen & 192.168 .30 .245 & \multirow{3}{*}{ Setting 2 2} & 0,0874 & 3 & Good \\
\hline 6 & staff & 192.168 .30 .245 & & 0,08117 & 3 & Good \\
\hline
\end{tabular}

Pada tabel 8menunjukkan perhitungan Quality of Service (QoS) delay pada setiap user mendapatkan nilai masih dibawah 1 ms. Maka mendapatkan kategori "GOOD” dengan nilai index " 3 " dengan range $0-75$ ms. Artinya variasi kedatangan data paket pada terminal tujuan sangat cepat sehingga akses internet lancar dan stabil.

Analisa manajemen bandwidth pada setting 1 dan setting 2 memiliki perbedaan pada Quality of Service (QoS) Throughput, dilihat dari table 6 hasil Throughput pada setting 2 lebih baik dari setting 1 . Hal ini dipengaruhi oleh perbedaan manajemen bandwith antara setting 1 dan setting 2. Setting 1 hanya pembatasan di user profile sedangkan setting 2 menggunakan fungsi mark packet dan queue tree, tentunya pada setting 2 pembagian lebih stabil dari setting 1 . Artinya pada setting 2 dan setting 1 untuk akses internet setting 2 lebih optimal daripada setting 1 .

Dalam analisa ini, secara umum nilai throughput pada setting 2 lebih besar dibandingkan dengan nilai throughput pada setting 1 . Hal ini berkaitan dimana pada dasarnya setting 1 untuk satu antrian hanya membatasi trafik 2 arah (upload dan download), sementara pada setting 2 upload dan download dibedakan dengan masing-masing konfigurasi. Selain itu, penurunan nilai throughput dapat disebabkan oleh beberapa faktor diantaranya perangkat jaringan, topologi jaringan atau induksi listrik dan cuaca.

Untuk Quality of Service (QoS) packet loss, delay, dan jitter didapatkan perhitungan yang selisih yang sangat sedikit. Pada setting 1 dan setting 2 untuk pengiriman data dan penerimaan data sangat cepat dan stabil.

\section{Kesimpulan}

Berdasarkan hasil penelitian yang telah dilakukan peneliti tentang Analisa Manajemen Bandwidth Indihome melalui IP Filter menggunakan Mikrotik Hap Lite di FT UNISKA, maka ditarik bahwa :

1. Perancangan setting manajemen bandwidth dibuat dengan 2 model setting antara lain manajemen bandwidth pada user profile dan manajemen bandwidth menggunakan mark packet dan queue tree.
2. Pengujian Quality of Service (QoS) dari kedua model setting menggunakan aplikasi speedtest dan wireshark versi 3.2.6. Pada pengujian menggunakan aplikasi speedtest bandwidth tidak melebihi batas limit yang ditentukan. Pada pengujian menggunakan aplikasi wireshark ditunjukkan perhitungan QoS Throughput setiap user didapatkan tidak lebih dari $100 \mathrm{Kbps}$, maka parameter standar menurut TIPHON dikategorikan "BAD" dengan index "0". Pada QoS packet loss setiap user didapatkan nilai 0 , maka parameter standar menurut TIPHON dikategorikan "PERFECT" dengan index "4". Pada QoS delay setiap user didapatkan nilai kurang dari 100 s, maka parameter standar menurut TIPHON dikategorikan "PERFECT" dengan index "4". Dan pada QoS jitter setiap user didapatkan nilai dibawah angka 1, maka parameter standar menurut TIPHON dikategorikan "GOOD” dengan index “ 3 ".

3. Pada perancangan manajemen bandwidth di penelitian ini sudah optimal. Hal ini dibuktikan dengan pengujian Quality of Service (QoS) menggunakan aplikasi speedtest dan wireshark versi 3.2.6.Hasil kedua aplikasi menunjukkan bandwidth tidak melebihi batas limit yang ditentukan pada perancangan.

\section{Daftar Pustaka}

[1] Saputra, R., "Bandwidth Managemen Mikrotik", Team Oksigen Office, Jakarta, 2012.

[2] Athailah, "Mikrotik Untuk Pemula", Penerbit Mediakita, Jakarta, 2013.

[3] Gunawan, A. H., "Quality of Service dalam Data Komunikasi. Online”, 2008.

[4] Sofana, Iwan, "Teori dan Modul Praktikum Jaringan Komputer”, Bandung, Modula, 2011.

[5] Jusak, "Teknologi Komunikasi Data Modern", Penerbit ANDI, Surabaya, 2012. 